\title{
Chapter 18 \\ Semi-automated Magnetic Bead-Based Antibody Selection from Phage Display Libraries
}

\author{
Zoltán Konthur, Jeannine Wilde, and Theam Soon Lim
}

\subsection{Introduction}

Antibodies are the fastest growing sector of biological therapeutics, and currently more than 400 monoclonal antibodies are in the pipeline (Dübel 2007). The quest to obtain human antibodies for therapy has led many researchers to design diverse display technologies as well as to generate larger and more diverse antibody display libraries (Mondon et al. 2008). Although many different display technologies have been introduced for human antibody generation, such as yeast display (Boder and Wittrup 1997), ribosome display (Hanes and Plückthun 1997) and mRNA display (Fukuda et al. 2006), phage display still remains the gold standard in human antibody generation (McCafferty et al. 1990; Barbas et al. 1991; Breitling et al. 1991). The accomplishment of phage display-derived human antibodies is highlighted by the increase of human antibody-based therapies being introduced into the market, and many more in clinical trials (Thie et al. 2008). Today, multiple companies exploit phage display technology worldwide for the development of therapeutic antibodies (Konthur 2007). Additionally, phage display of antibody libraries is being increasingly appreciated for the development of research reagents and a number of national and international initiatives already apply this method for antibody generation (Konthur et al. 2005; Taussig et al. 2007).

\footnotetext{
Z. Konthur $(\triangle)$ and J. Wilde

Department of Vertebrate Genomics, Max Planck Institute for Molecular Genetics, Ihnestrasse 73, Berlin 14195, Germany

e-mail: konthur@molgen.mpg.de; wilde@molgen.mpg.de

T.S. Lim

Department of Vertebrate Genomics, Max Planck Institute for Molecular Genetics, Ihnestrasse 73, Berlin 14195, Germany

Free University Berlin, Faculty of Biology, Chemistry and Pharmacy, Takustrasse 3, Berlin 14195, Germany

Institute for Research in Molecular Medicine, Universiti Sains Malaysia, 11800 Penang, Malaysia e-mail: lim@molgen.mpg.de
} 
In phage display, panning is an iterative process, where specific binder molecules are continuously enriched and multiplied from a pool of predominantly nonbinders until the specific binders finally become the majority population (Konthur and Crameri 2003). This "panning" method has been referred to the tool used by gold washers to isolate gold (Parmley and Smith 1988). For panning, antigens can be anchored to various types of solid supports, such as magnetic beads (Walter et al. 2001), column matrix (Noppe et al. 2009), nitrocellulose (Hawlisch et al. 2001) or to a larger extent, plastic surfaces in the form of polystyrene tubes (Hust et al. 2002), or 96 well polystyrene microtiter plates (Krebs et al. 2001). The selection process is an affinity-based enrichment process and involves multiple rounds of selection. The antibody presenting phage particles are incubated with the immobilized antigens to allow interactions to occur. Next, nonbinders are removed from the selection matrix by washing off unbound phage particles. The bound phages are then used to infect Escherichia coli and are subsequently re-amplified to be used in the following round. This selection cycle is normally repeated until a satisfactory enrichment is achieved. Normal panning protocols usually constitute between two and four rounds. The infection of $E$. coli with phage particles along with the propagation of antibody presenting phages is a fairly robust but nevertheless laborious biological process involving multiple steps, which need to be performed with care, and is genuinely regarded as difficult to fully automate.

By definition, an automated system refers to pipelines in which all steps of the process or assay is carried out without any human intervention (Cohen and Trinka 2002). In contrast, unit automation requires human involvement in certain stages, and only individual stages in the process pipeline are partially automated independent of each other (Menke 2002). As the entire technology is a compilation of various stages of work, to structure the workflow in a fully automated fashion is indeed challenging in terms of compatibility and cost. Key stages in the selection procedure are panning, infection, propagation, colony picking, and ELISA evaluations. Principally, almost all stages can be automated, but the extent of the automation should be within the financial resources available. In practice, the extent of laboratory automation is dependent upon the scope and timeline of the project pursued (Hamilton 2002).

Despite the technology's potential in high-throughput platforms being regarded as low (Li 2000), the growing interest for human antibodies has kick-started various initiatives to streamline the processes involved in phage display. Automation and high-throughput approaches are required to circumvent the need for faster and more efficient screening protocols and to allow simultaneous selection and evaluation of enriched antibody phage libraries. For most of these methods, individual attempts to automate panning, colony picking, and ELISA have been successful (Buckler et al. 2008).

Possible panning procedures compatible with automation involve immobilization of antigens to either 96 well microtiter plates (Krebs et al. 2001) or magnetic beads (Walter et al. 2001). In microtiter plates, immobilization of antigens is carried out in two ways, by adsorption of the antigens to the plate surface, or in a directed 
fashion using, for example, streptavidin-coated plates to capture biotinylated antigens. Alternatively, antigens can be attached to magnetic beads. The main advantage of magnetic beads against microtiter plates is the increase in surface area, leading to a more efficient panning process. Magnetic particles have been shown to be more efficient than polystyrene plates in the panning process (McConnell et al. 1999) and to assist in ELISA experiments detecting antigens otherwise not detected by conventional ELISA (Kala et al. 1997).

We use a pin-based magnetic particle processor (Kingfisher, Thermo) for unitautomation of the panning procedure, which enables the handling of 96 magnetic pins, corresponding to the positions of a 96-well microtitre plate (Walter et al. 2001; Rhyner et al. 2003). The processor can accommodate several microtitre plates filled with individual buffers for washing and incubation as depicted in Fig. 18.1a. The individual steps of the panning procedure are performed by transferring the magnetic particles between wells with rod-shaped magnets covered with plastic caps by a sequence of capture and release motions (Fig. 18.1b). The movements are software-driven and parameters such as time, position, frequency, and strength of shaking movements can be adjusted, allowing reproducible control of each step of the phage display selection protocol for as many as 96 parallel selections. In our eyes, using a magnetic bead-based, instead of a microtiter plate-based selection scheme has an additional advantage. Moving the magnetic particles from vessel to vessel reduces the background of unspecific binders to the surfaces and transfers minimal volumes. Changing solutions in microtiter plates with a liquid handling robot always leaves a dead volume of liquid behind and a background of nonspecific binders can occur (Konthur and Walter 2002).

Our panning procedure is generally carried out using a magnetic particle processor over four rounds of selection (Fig. 18.1, Tables 18.1 and 18.2). Applying the processor allows standardization of panning parameters, such as washing conditions, incubation times, or to perform parallel selections on same targets under different buffer conditions. To keep things simple, we have not attempted to fully automate the selection process. Instead, we followed a unit-automation approach to the extent where it is easy and straightforward to do, as all steps require human intervention. However, setting up standard operating procedures and adapting all biological processes to 96-well microtiter plate format, manipulation by hand is kept as simple as possible and can be easily performed with multichannel pipettes reducing handling errors. The whole protocol has been streamlined to carry out bead loading, phage selection, phage amplification between selection rounds, and ELISAs for confirmation of binding activity in microtiter plate format. Once the phage display panning procedure is completed, the evaluation process to identify positive monoclonal antibodies is performed over two stages of ELISA. The first stage of evaluation is carried out on polyclonal level, in which the selection rounds are tested for target-specific enrichment of binders using a magnetic bead-based ELISA protocol (Fig. 18.2, Table 18.3). At the second stage, a set of monoclonal binders from individual selection rounds (chosen according to the results of the polyclonal ELISA) are analyzed for special binding by ELISA (Fig. 18.3). 


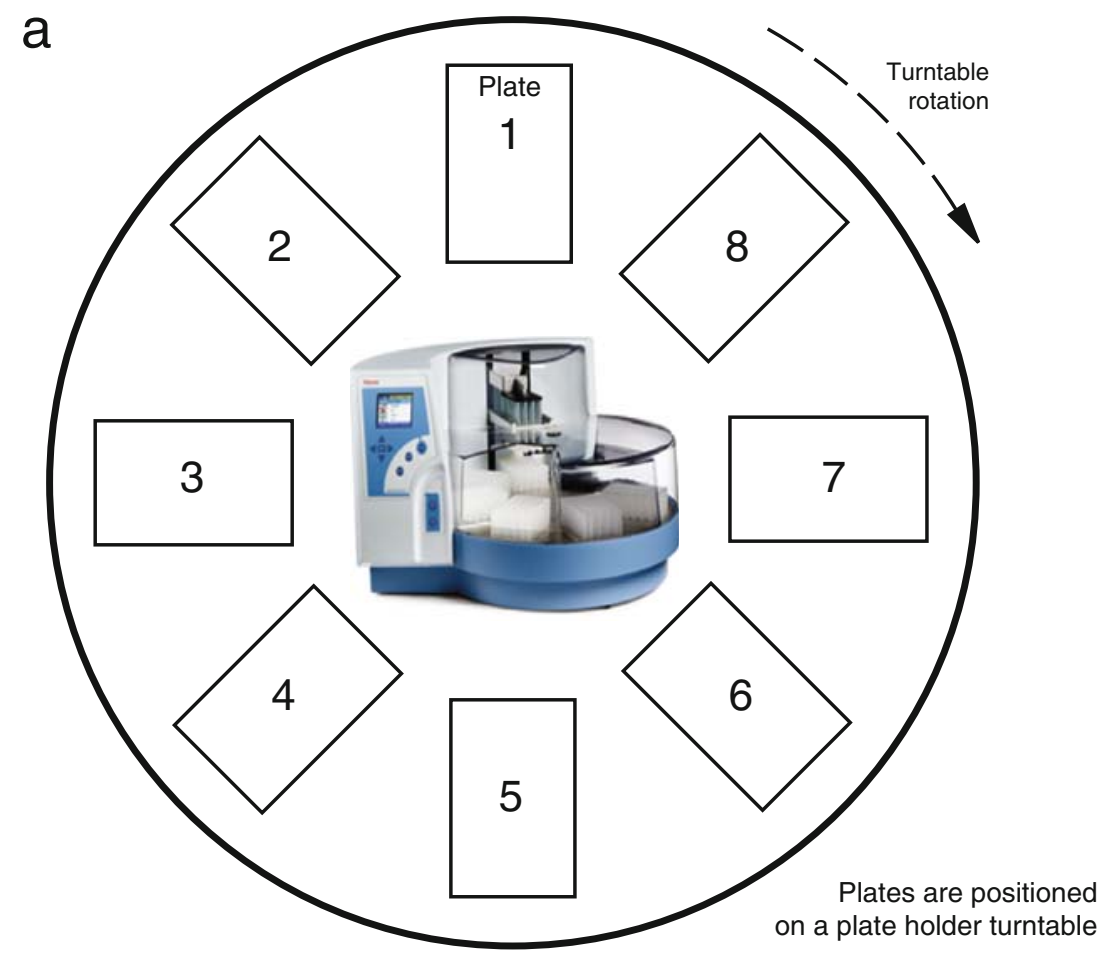

b
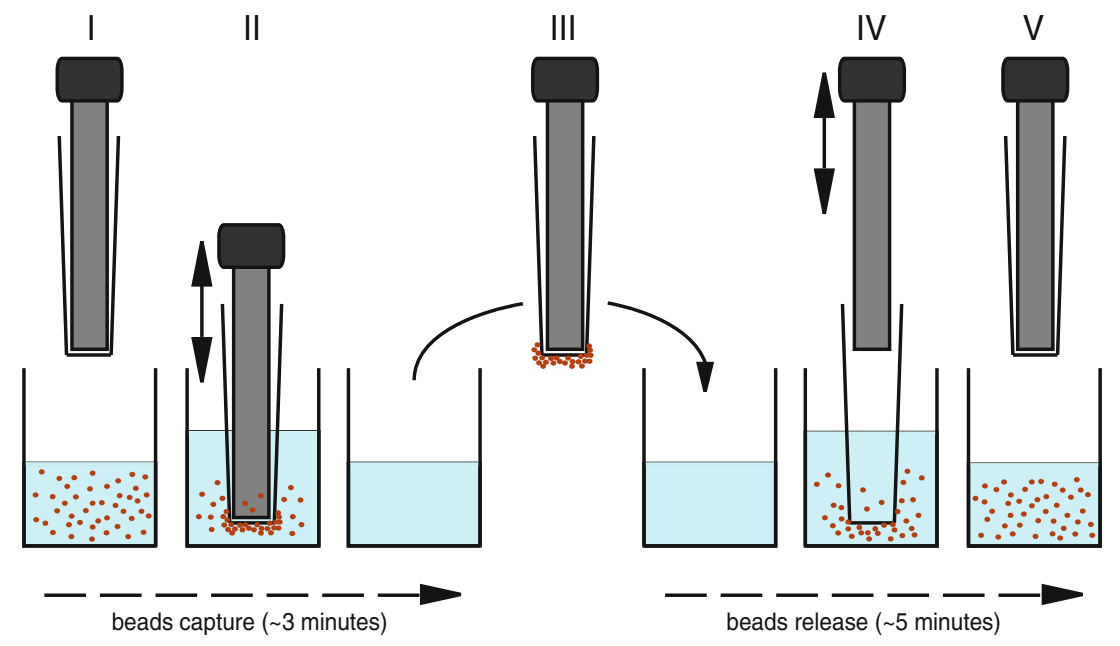

Position 1

Position 2

Fig. 18.1 Principle of the magnetic particle processor. (a) Rotating table of a Kingfisher 96 magnetic particle processor. The magnetic head is at a fixed loading position. For moving beads 
Table 18.1 Overview of automated magnetic bead-based panning procedure on a Kingfisher 96

\begin{tabular}{lllll}
\hline Plate no. & Panning round 1 & Panning round 2 & Panning round 3 & Panning round 4 \\
\hline 1 & Bead plate & Bead plate & Bead plate & Bead plate \\
2 & Phage plate & Phage plate & Phage plate & Phage plate \\
3 & Wash plate 1 & Wash plate 1 & Wash plate 1 & Wash plate 1 \\
4 & Release plate & Wash plate 2 & Wash plate 2 & Wash plate 2 \\
5 & E. coli culture plate & Release plate & Wash plate 3 & Wash plate 3 \\
6 & - & E. coli culture plate & Release plate & Wash plate 4 \\
7 & - & - & E. coli culture plate & Release plate \\
8 & - & - & - & E. coli culture plate \\
Total time: & $\sim 135 \mathrm{~min}$ & $\sim 145 \mathrm{~min}$ & $\sim 155 \mathrm{~min}$ & $\sim 165$ min \\
\hline
\end{tabular}

Table 18.2 Automated magnetic bead-based panning protocol (round 4) for Kingfisher 96

\begin{tabular}{|c|c|c|c|c|}
\hline $\begin{array}{l}\text { Plate } \\
\text { no. }\end{array}$ & Plate name & Work step & $\begin{array}{l}\text { Volume } \\
(\mu \mathrm{L})\end{array}$ & $\begin{array}{l}\text { Time } \\
(\min )\end{array}$ \\
\hline 1 & Bead plate & $\begin{array}{l}\text { Blocking of antigen-loaded and control } \\
\text { magnetic beads with PTM }\end{array}$ & 200 & 60 \\
\hline 2 & Phage plate & $\begin{array}{l}\text { Incubation of magnetic beads in antibody } \\
\text { phage stocks of the selection rounds }\end{array}$ & 200 & 60 \\
\hline 3 & Wash plate 1 & Wash 1 of magnetic beads in PBST & 200 & 10 \\
\hline 4 & Wash plate 2 & Wash 2 of magnetic beads in PBST & 200 & 10 \\
\hline 5 & Wash plate 3 & Wash 3 of magnetic beads in PBST & 200 & 10 \\
\hline 6 & Wash plate 4 & Wash 4 of magnetic beads in PBST & 200 & 10 \\
\hline 7 & Release plate & $\begin{array}{l}\text { Waiting position for magnetic beads until } \\
\text { E. coli culture plate is ready for infection }\end{array}$ & 200 & $5-10$ \\
\hline 8 & $\begin{array}{l}\text { E. coli culture } \\
\text { plate }\end{array}$ & $\begin{array}{l}\text { Infection of } E \text {. coli TG1 culture with bead- } \\
\text { bound phage particles }\end{array}$ & 200 & $-{ }^{\mathrm{b}}$ \\
\hline \multicolumn{4}{|c|}{ Total time: } & 170 \\
\hline
\end{tabular}

${ }^{\mathrm{a}}$ At this stage, $10 \mu \mathrm{l}$ bead-bound phage solution can be collected for titration. (see Sect. 18.3.4)

${ }^{\mathrm{b}}$ Incubation takes place outside Kingfisher 96 Instrument at $37^{\circ} \mathrm{C}$

In summary, automating the panning process on its own can largely increase the number of targets against which antibodies are selected in parallel, but it also shifts the bottleneck of the overall selection pipeline further toward the isolation and evaluation of monospecific binders. Isolation and screening of monoclonal binders can be readily automated, and multiple strategies have been reported (de Wildt et al.

\footnotetext{
Fig. 18.1 (continued) from plate to plate, the beads are recovered from one plate and then the new plate is moved to the loading position by rotating the plate holder table clockwise. Photograph shows the latest model: Kingfisher Flex instrument, Thermo Scientific. (b) Operating mode of magnetic particle processors. (I) The rod-shaped magnet is covered by a plastic cap and moves into a solution containing suspended magnetic beads. (II) Moving slowly up and down, the beads are attracted to the cover, and (III) by moving the covered magnet to the next position, the beads are transferred to a new solution. (IV) Once the magnet is removed from the cap, the beads are slowly suspended again. (V) The magnet head and plastic covers are raised to the starting position to proceed to the next stage of the process
} 

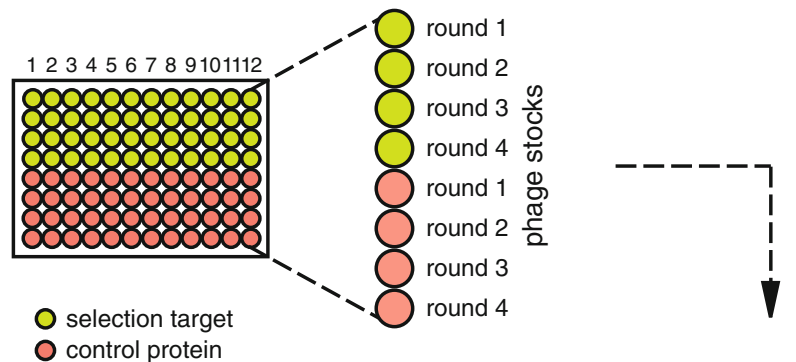

anti-GRB2 Polyclonal Antibody Phage ELISA on Magnetic Beads

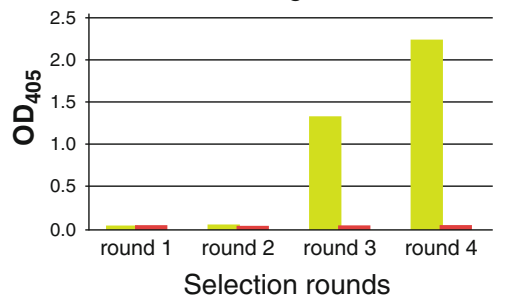

Fig. 18.2 Magnetic particle ELISA for monitoring polyclonal antibody phage enrichment. On the left, the plate layout for 12 individual selections is shown. For each selection, the phage stock solutions are split and pipetted into the positions A-D and E-H of the same column, respectively. Next, selection target-coated or control protein-coated magnetic beads are added to the phage solutions as indicated. All steps of the ELISA are performed in a 96-well magnetic particle processor. On the right, the enrichment of specifically binding antibody phage during four rounds of selection on GRB2 is shown. Specific enrichment is seen in rounds 3 and 4

Table 18.3 Automated magnetic bead-based polyclonal antibody ELISA protocol for Kingfisher 96

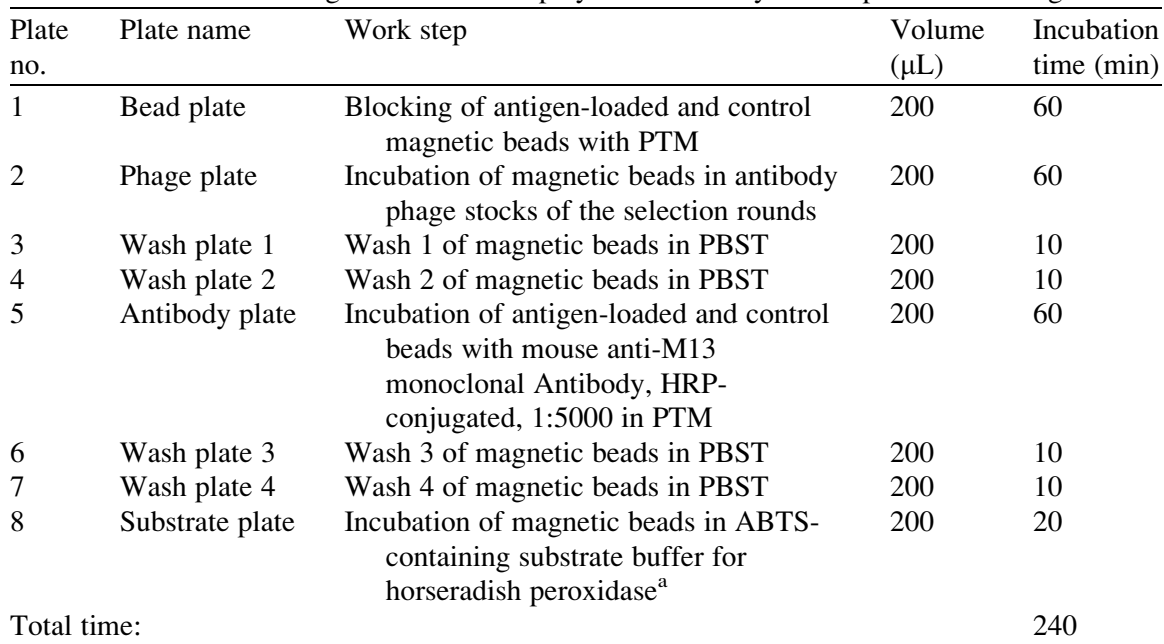

${ }^{a}$ Prior to measurement of extinction, beads are transferred back to Wash plate 4 


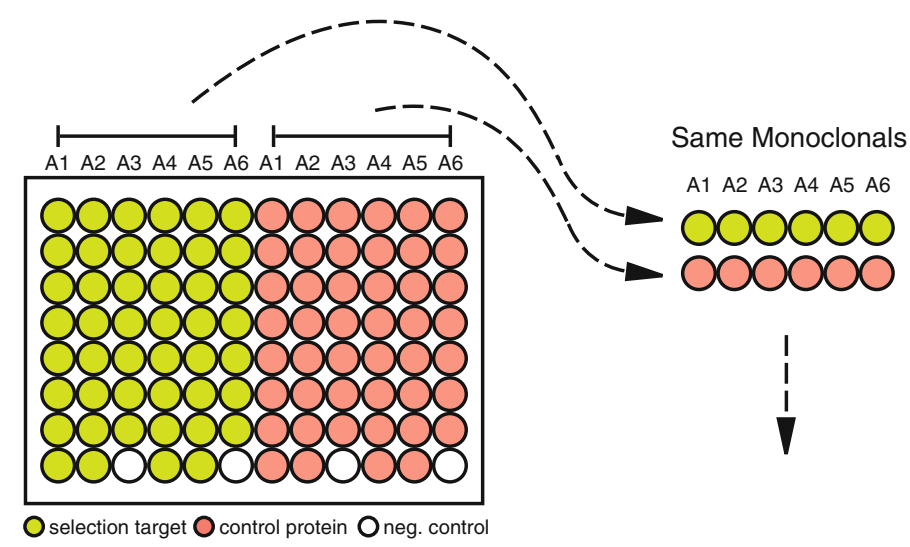

ELISA results of 46 anti-eGFP Soluble Monoclonal Antibody Fragments

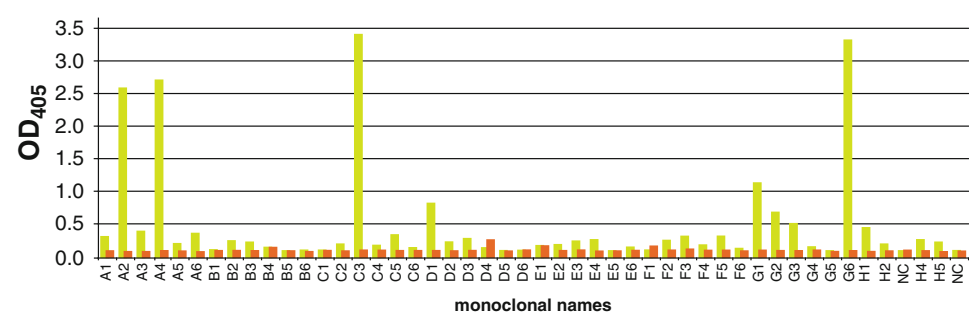

Fig. 18.3 ELISA design for evaluation of 46 soluble monoclonal antibody fragments. On the top, the layout for antigen coating is shown. The soluble monoclonal antibody fragments of the plate positions A1-H6 (or A7-H12, respectively) are added to each half of the Assay plate. On the bottom, the results for 46 anti-eGFP soluble antibody fragments are shown. All clones with a $>$ tenfold signal to background ratio are considered as positive. In this case, all clones with an $\mathrm{OD}_{405}>1.0$

2000; Krebs et al. 2001; Hallborn and Carlsson 2002; Buckler et al. 2008; Turunen et al. 2009).

\subsection{Materials}

\subsubsection{Loading of Magnetic Beads}

- Dynabeads ${ }^{\circledR}$ M-280 Streptavidin (Invitrogen Dynal AS, Oslo, Norway)

- Phosphate-buffered saline (PBS): $8 \mathrm{~g} / \mathrm{L} \mathrm{NaCl}, 0.2 \mathrm{~g} / \mathrm{L} \mathrm{KCL}, 1.44 \mathrm{~g} / \mathrm{L}$ $\mathrm{Na}_{2} \mathrm{HPO}_{4} \cdot 2 \mathrm{H}_{2} \mathrm{O}$, and $0.24 \mathrm{~g} / \mathrm{L} \mathrm{KH} \mathrm{K}_{2} \mathrm{PO} 4$, pH 7.4

- Phosphate-buffered saline Tween (PBST): PBS + 0.1\% Tween-20 


\subsubsection{Semi-automated Panning using a Magnetic Particle Processor}

- E. coli TG1, genotype: K12 $\Delta$ (lac-proAB) supE thi hsdD5/F' traD36 proA+B lacIq lacZ $\triangle M 15$

- 96-well V-bottom polypropylene (PP) microtiter plates (Nunc, Wiesbaden, Germany)

- 96-well U-bottom polypropylene (PP) microtiter plates (Nunc, Wiesbaden, Germany)

- AeraSeal breathable sealing film (Sigma-Aldrich, Taufkirchen, Germany)

- Phosphate-buffered saline Tween Milkpowder (PTM): PBS + 1\% Tween$20+2 \%$ nonfat dry milkpowder, prepare fresh

- 2YT medium: $1.6 \%(\mathrm{w} / \mathrm{v})$ tryptone, $1 \%(\mathrm{w} / \mathrm{v})$ yeast extract, and $0.5 \% \mathrm{NaCl}$, $\mathrm{pH} 7.0$

- 10× Amp/Glu solution: $1 \mathrm{mg} / \mathrm{mL}$ ampicilin, and 20\% (w/v) glucose in $2 \mathrm{YT}$ medium

\subsubsection{Packaging of Phagemids}

- M13K07 Helperphage (New England BioLabs, Frankfurt, Germany)

- 96-well filtration plate: MultiScreen ${ }_{\text {HTS }}$ Plates with hydrophilic Durapore PVDF membrane with $0.65 \mu \mathrm{m}$ pore size (Millipore, Schwalbach/Ts, Germany)

- 2YT-AG-2: 2YT medium containing $100 \mu \mathrm{g} / \mathrm{mL}$ ampicilin, 2\% (w/v) glucose

- 2YT-AKG: 2YT medium containing $100 \mu \mathrm{g} / \mathrm{mL}$ ampicilin, $60 \mu \mathrm{g} / \mathrm{mL}$ kanamycin, $0.1 \%(\mathrm{w} / \mathrm{v})$ glucose

- Glycerol solution: $80 \%(w / v)$

\subsubsection{Titration of Phage Particles}

- 2YT-AG agar plates: 2YT medium containing $100 \mu \mathrm{g} / \mathrm{mL}$ ampicilin, $2 \%(\mathrm{w} / \mathrm{v})$ glucose, and $1.5 \%(\mathrm{w} / \mathrm{v})$ agar-agar

- 2YT-K agar plates: 2YT medium containing $60 \mu \mathrm{g} / \mathrm{mL}$ kanamycin, and $1.5 \%$ (w/v) agar-agar

\subsubsection{Magnetic Particle ELISA of Polyclonal Antibody Phage}

- Matrix 96-well polystyrene microtiter plates (Thermo Scientific, Dreieich, Germany) 
- Anti-M13, horseradish peroxidise (HRP)-conjugated monoclonal antibody (GE Healthcare, München, Germany)

- Substrate buffer: $50 \mathrm{mM}$ citrate buffer, $\mathrm{pH}$ 4.3. Mix 1:2 $50 \mathrm{mM}$ trisodium citrate and $50 \mathrm{mM}$ citric acid shortly before use

- ABTS (2,2'-azino-bis (3-ethylbenzthiazoline 6-sulfonic acid) diammonium tablets (Sigma, Deisenhofen, Germany)

- Hydrogen peroxide (Perhydrol, 30\% $\mathrm{H}_{2} \mathrm{O}_{2}$; Merck, Darmstadt, Germany)

\subsubsection{Production of Soluble Monoclonal Antibody Fragments in Microtiter Plates}

- E. coli HB2151, genotype: $\mathrm{K} 12$ ara $\Delta$ (lac-proAB) thi $/ \mathrm{F}^{\prime}$ proA $+B$ lacIq lacZ $\triangle M 15$

- 2YT-AG-0.1: 2YT medium containing $100 \mu \mathrm{g} / \mathrm{mL}$ ampicilin, $0.1 \%$ (w/v) glucose

- $20 \mathrm{mM}$ isopropyl- $\beta$-D-thiogalactopyranoside (IPTG)

\subsubsection{ELISA of Soluble Monoclonal Antibody Fragments in Microtiter Plates}

- Bovine Serum Albumin (BSA): $10 \mathrm{mg} / \mathrm{mL}$ stock solution in PBS

- Recombinant Protein L, horseradish peroxidise (HRP)-conjugated (Pierce, Thermo Scientific, Bonn, Germany)

\subsection{Methods}

All the protocols in this section are designed to allow handling of multiple selection targets in parallel. The protocols were set up with the human single-fold $\mathrm{scFv}$ libraries, I and J (MRC Cambridge, UK; see Sect. 18.5, Note 1). The complete phage display selection procedure could be streamlined to require only minimal user intervention. Conventional panning procedures require repetitive rounds of tedious phage infection and propagation, which makes large sample screening cumbersome. With the standard operating procedures and standardized templates outlined here, the migration from automated selection to manual biological processes throughout the selection procedure becomes straightforward. The 96-well microtiter plate layout allows the protocol to be adaptable for manual use by employing multichannel pipettes. When applied, the semi-automated method will provide high-throughput results with maximum convenience and minimal handling. 


\subsubsection{Loading of Magnetic Beads}

This protocol provides sufficient antigen-coated beads per target to perform up to five rounds of semi-automated panning for antibody phage enrichment and the following polyclonal antibody phage ELISA (see Sect. 18.3.5). All steps are carried out in $1.5 \mathrm{~mL}$ Eppendorf cups and for ease of use, a magnetic stand and rotator is required (see Sect. 18.5, Note 2).

1. Take $1 \mathrm{mg}(100 \mu \mathrm{L})$ Dynabeads M-280 Streptavidin magnetic beads and wash $3 \times 5 \mathrm{~min}(\mathrm{~min})$ with $1.5 \mathrm{~mL}$ PBST and $1 \times 5 \mathrm{~min}$ with $1.5 \mathrm{~mL}$ PBS at room temperature (RT). Meanwhile, dissolve (a) 100-200 $\mu \mathrm{g}$ biotinylated protein antigen (see Sect. 18.5, Note 3) in $1 \mathrm{~mL}$ PBS, or alternatively, (b) 1-2 $\mu \mathrm{g}$ biotinylated peptide antigen in $1 \mathrm{~mL}$ PBS. Discard wash solution, resuspend magnetic beads gently in the $1 \mathrm{~mL}$ antigen solution, and incubate for $1 \mathrm{~h}$ at RT on a rotator. Alternatively, the incubation can be performed overnight at $4^{\circ} \mathrm{C}$ on a rotator

2. Take off antigen solution and wash magnetic beads $3 \times 5$ min with $1.5 \mathrm{~mL}$ PBST

3. Finally, discard last wash solution, resuspend magnetic beads in $200 \mu \mathrm{L}$ PBS, and store antigen-loaded bead stock until further use at $4^{\circ} \mathrm{C}$

\subsubsection{Semi-automated Panning on Magnetic Particle Processor}

For simplicity, the protocol refers to parallel selection on 12 antigens, which will be arranged throughout the whole protocol in the positions A1-A12 of a 96 well microtiter plate used in a Kingfisher 96 instrument. The number of plates and steps for each selection round is summarized in Table 18.1. As an example, the automated magnetic bead-based panning protocol on the Kingfisher 96 for the fourth round of selection is summarized in Table 18.2. If more or fewer selections are performed in parallel, add or remove microtiter plate positions accordingly.

Since the selection of specific binders occurs on magnetic beads, the microtiter plates are only reaction vessels. Therefore, the magnetic bead-based selection protocol can, in principle, be applied in all available magnetic particle processors employing the basic concept of moving beads from vessel to vessel (Fig. 18.1b).

1. Inoculate $5 \mathrm{~mL}$ of $2 \mathrm{YT}$ in a $15 \mathrm{~mL}$ polypropylene tube with a single clone of TG1 from an agar plate and grow shaking overnight at $37^{\circ} \mathrm{C}$ and $250 \mathrm{rpm}$ (see Sect. 18.5, Note 4)

2. Inoculate $50 \mathrm{~mL} 2 \mathrm{YT}$ in a $250 \mathrm{~mL}$ Erlenmeyer flask with $0.5 \mathrm{~mL}$ of a fresh overnight TG1 culture and incubate shaking at $37^{\circ} \mathrm{C}$ and $250 \mathrm{rpm}$ until $\mathrm{OD}_{600}=$ 0.4-0.5 (see Sect. 18.5, Note 5) 
3. Arrange bead-plate. Fill positions A1-A12 of a 96-well V-bottom PP (PP) microtiter plate with $180 \mu \mathrm{L}$ PTM, and for each antigen, add $20 \mu \mathrm{L}$ from corresponding antigen-loaded bead stocks (see Sect. 18.3.1) to specified position. Add magnetic beads of antigen 1 to positions A1, beads of antigen 2 to positions A2, and so on

For the first round of selection, continue with step 4. For later selection rounds, continue with step 7

4. Preincubate unselected antibody phage library with empty magnetic beads in PTM to deplete selection matrix binders. In a $15 \mathrm{~mL}$ PP tube, add $2 \mathrm{mg}$ $(200 \mu \mathrm{L})$ Dynabeads M-280 Streptavidin to $1 \times 10^{13}-3 \times 10^{13}$ phage particles in $10 \mathrm{~mL}$ PTM. Incubate for $1-2 \mathrm{~h}$ at $\mathrm{RT}$ on a rotator

5. Collect beads at the bottom of the tube by 2 min centrifugation, 2,000 rpm, and carefully transfer antibody phage library solution to a new $15 \mathrm{~mL}$ PP tube. Discard magnetic beads

6. Arrange phage-plate for first round. Fill positions A1-A12 of a 96-well V-bottom PP microtiter plate with $200 \mu \mathrm{L}$ of the antibody phage library solution. Continue with step 8

7. Arrange phage-plate for remaining rounds. Fill positions A1-A12 of a 96-well V-bottom PP microtiter plate with $100 \mu \mathrm{L}$ PTM. Add $100 \mu \mathrm{L}$ of the amplified phage solutions of the previous round (see Sect. 18.3.3) according the same antigen order in positions A1-A12

8. Prepare wash plate(s). Fill positions A1-A12 of a 96-well V-bottom PP microtiter plates with $200 \mu \mathrm{L}$ PBST. Adjust number of plates according to Table 18.1 (see Sect. 18.5, Note 6)

9. Prepare release plate. Fill positions A1-A12 of a 96-well V-bottom PP microtiter plates with $200 \mu \mathrm{L}$ PBS

10. Place plates in the Kingfisher 96 instrument according to the plate positions in Table 18.1 and start magnetic bead-based panning program. The program should be set to move magnetic beads from plate to plate and incubate the beads in each plate as indicated in Table 18.2. During all incubations, the beads should be kept in suspension by moving plastic tips up and down in the wells at medium speed $(30-50 \mathrm{~mm} / \mathrm{s})$. The program ends by releasing the beads in the release plate (see Sect. 18.5, Notes 7 and 8)

11. Once the panning program has finished, prepare E. coli culture plate. Fill positions A1-A12 of a 96-well U-bottom PP microtiter plates with $200 \mu \mathrm{L}$ of E. coli TG1 $\left(\mathrm{OD}_{600}=0.4-0.5\right)$, place E. coli culture plate in Kingfisher 96 instrument and start Transfer Program. This program simply transfers the beads from the release plate to the $E$. coli culture plate

12. Take out selection stock plate from the Kingfisher 96 instrument, cover with plastic lid, and incubate for $30 \mathrm{~min}$ at $37^{\circ} \mathrm{C}$ (see Sect. 18.5, Note 9)

13. Add $20 \mu \mathrm{L} 10 \times$ Amp/Glu solution, seal with breathable sealing film, and incubate in a microplate shaker for $2 \mathrm{~h}$ at $37^{\circ} \mathrm{C}$ and $1,400 \mathrm{rpm}$ (see Sect. 18.5, Note 10)

14. Directly proceed with Packaging of Phagemids protocol, Sect. 18.3.3 


\subsubsection{Packaging of Phagemids}

The steps described in this section are directly connected to the semi-automated selection protocol in Sect. 18.3.2. If packaging of phagemids from glycerol stock plates is required, see Sect. 18.5, Note 11.

1. Take selection stock plate from Sect. 18.3.2, and add $200 \mu \mathrm{L}$ of prewarmed 2 YT-AG- 2 medium $\left(37^{\circ} \mathrm{C}\right)$ to culture, mix thoroughly, and transfer $200 \mu \mathrm{L}$ into 96-well filtration plate. Seal selection stock plate again with breathable sealing film and continue incubation in a microplate shaker overnight at $37^{\circ} \mathrm{C}$ and $1,200 \mathrm{rpm}$

2. To the filtration plate, add $20 \mu \mathrm{L}$ M13K07 helperphage ( $\sim 10^{9}$ phage particles), cover with plastic lid, and incubate stationary for $30 \mathrm{~min}$ at $37^{\circ} \mathrm{C}$ (see Sect. 18.5, Note 12)

3. Place filtration plate on top of a 96-well U-bottom PP microtiter plate and fix with sticky tape. Prepare a counter balance plate in similar fashion

4. Filter bacterial culture by centrifugation in microtiter plate holders (swing out rotor) for 2-5 min at 2,000 rpm (see Sect. 18.5, Note 13)

5. Discard filtrate with remaining M13K07 helperphage

6. Resuspend bacteria in $220 \mu \mathrm{L}$ prewarmed $2 \mathrm{YT}-\mathrm{AKG}\left(30^{\circ} \mathrm{C}\right)$ and transfer to a fresh 96-well U-bottom PP microtiter plate. Seal phage production plate with breathable sealing film and incubate in a microplate shaker overnight at $30^{\circ} \mathrm{C}$ shaking at $1,400 \mathrm{rpm}$

7. The next day, add $160 \mu \mathrm{L}$ glycerol solution to selection stock plate, mix, and store as glycerol stock at $-80^{\circ} \mathrm{C}$

8. Pellet bacteria in phage production plate by centrifugation for $10 \mathrm{~min}$ at 2,000 rpm. Transfer supernatant carefully without disturbing the pellet to a 96-well filtration plate

9. Place filtration plate on top of a new 96-well U-bottom PP microtiter plate and fix with sticky tape

10. Filter antibody presenting phage particles to remove possible contaminating E. coli cells by centrifugation for $2-5 \mathrm{~min}$ at $2,000 \mathrm{rpm}$

11. Store filtrate (phage stock plate) and discard bacteria pellets and used filtration plate

12. Add $50 \mu \mathrm{L}$ PBS to each well of the phage stock plate and mix thoroughly. Use $100 \mu \mathrm{L}$ for the next round of selection (see Sect. 18.3.2), use $10 \mu \mathrm{L}$ for phage titration (see Sect. 18.3.4). Seal phage stock plate carefully with sticky tape and store until further use at $4^{\circ} \mathrm{C}$

\subsubsection{Titration of Phage Particles}

During the selection process, the success of phage particle amplification before each following selection round is monitored by titration. Additionally, the titer of 
bead-bound antibody phages during panning can also be monitored (see Sect. 18.5, Note 8).

1. Inoculate $5 \mathrm{~mL}$ of $2 \mathrm{YT}$ in a $15 \mathrm{~mL} \mathrm{PP}$ tube with a single clone of TG1 from an agar plate and grow, shaking overnight at $37^{\circ} \mathrm{C}$ and $250 \mathrm{rpm}$ (see Sect. 18.5, Note 4)

2. Inoculate $50 \mathrm{~mL} 2 \mathrm{YT}$ in a $250 \mathrm{~mL}$ Erlenmeyer flask with $0.5 \mathrm{~mL}$ of overnight TG1 culture and incubate, shaking at $37^{\circ} \mathrm{C}$ and $250 \mathrm{rpm}$ until $\mathrm{OD}_{600}=0.4-0.5$ (see Sect. 18.5, Note 5)

3. Prepare a $1: 10$ serial dilution (until $10^{-9}$ ) of enriched phage libraries from selection rounds (phage stock plate, see Sect. 18.3.3) by adding $10 \mu \mathrm{L}$ phage to $90 \mu \mathrm{L}$ PBST in a 96-well U-bottom PP microtiter plate (see Sect. 18.5, Note 12)

4. Add $100 \mu \mathrm{L}$ of $E$. coli $\mathrm{TG} 1\left(\mathrm{OD}_{600}=0.4-0.5\right)$ to phage dilutions $10^{-5}-10^{-9}$, cover with plastic lid, and incubate stationary for $30 \mathrm{~min}$ at $37^{\circ} \mathrm{C}$

5. Mix infected $E$. coli cultures and plate $10 \mu \mathrm{L}$ droplets of each dilution series on a single 2YT-AG and 2YT-K agar plates per enriched library. Once droplets are dried, incubate plates top-down overnight at $37^{\circ} \mathrm{C}$ (see Sect. 18.5, Note 14)

6. Next day, count the number of colonies in the droplets on all plates, and calculate from these the colony forming units (infectious phage particles/mL) using the formula:

$$
\text { c.f.u. }=\text { numberofcolonies } \times \text { dilutionfactor } \times 100
$$

On an average, phage preparations in microtiter plates (200 $\mu \mathrm{L}$ culture volume) produce $10^{10}-10^{11}$ c.f.u.

7. Compare the c.f.u. values obtained on 2YT-AG and 2YT-K agar plates for each phage library. The helperphage genome containing population should be a minimum of 4-5 orders of magnitude smaller than the antibody fragment containing phagemid population

\subsubsection{Magnetic Particle ELISA of Polyclonal Antibody Phage}

The polyclonal antibody phage ELISA for evaluation of enrichment success is performed using a magnetic particle processor to maintain similar conditions as the initial selection process. At a maximum, polyclonal ELISA for 12 independent selections over four rounds can be performed simultaneously with the appropriate negative control. Proposed plate layout for 12 ELISAs in parallel and an example of a polyclonal ELISA result are shown in Fig. 18.2. The ELISA protocol on the Kingfisher 96 instrument takes $4 \mathrm{~h}$ and is summarized in Table 18.3.

1. Arrange bead-plate. Fill each position of a 96-well V-bottom PP microtiter plate with $180 \mu \mathrm{L}$ PTM and add $20 \mu \mathrm{L}$ of antigen-loaded bead stock (see 
Sect. 18.3.1) according to plate layout in Fig. 18.2. Add magnetic beads of antigen 1 to positions A1-D1, beads of antigen 2 to positions A2-D2, and so on

2. As negative control, empty beads are used. Take $5 \mathrm{mg}(500 \mu \mathrm{L})$ Dynabeads M-280 Streptavidin magnetic beads and wash $3 \times 5$ min with $1.5 \mathrm{~mL}$ PBST and $1 \times 5 \mathrm{~min}$ with $1.5 \mathrm{~mL}$ PBS at RT. Discard last wash solution and resuspend in $1 \mathrm{~mL}$. Add $20 \mu \mathrm{L}$ to positions E1-H12

3. Arrange phage-plate. Fill each position of a 96-well V-bottom PP microtiter plate with $150 \mu \mathrm{L}$ PTM. Add $50 \mu \mathrm{L}$ of phage solution from the phage stock plates of the individual rounds to plate according layout in Fig. 18.2. Add phage stocks of selection rounds $1-4$ on antigen 1 to position A1-D1 and E1-H1, respectively. Add phage stocks of selection rounds 1-4 on antigen 2 to position A2-D2 and E2-H2, respectively, and so on

4. Prepare wash plates 1-3. Fill 96-well V-bottom PP microtiter plates with $200 \mu \mathrm{L}$ PBST

5. Prepare wash plate 4. Fill 96-well V-bottom PP microtiter plates with $200 \mu \mathrm{L}$ PBS

6. Prepare antibody plate. Add $4 \mu \mathrm{L}$ mouse monoclonal anti-M13, HRPconjugated, to $20 \mathrm{~mL}$ PTM (1:5,000). Fill 96-well V-bottom PP microtiter plates with $200 \mu \mathrm{L}$ antibody solution

7. Place plates in the Kingfisher 96 instrument and start magnetic bead-based ELISA program. The program should be set to move magnetic beads from plate to plate and incubate the beads in each plate as indicated in Table 18.3. During all incubations, the beads should be kept in suspension by moving plastic tips up and down in the wells at medium speed $(30-50 \mathrm{~mm} / \mathrm{s})$

8. While ELISA program is running, prepare substrate plate. Dissolve one ABTS tablet $(10 \mathrm{mg})$ in $20 \mathrm{~mL}$ substrate buffer. Shortly after the antibody plate incubation step in the ELISA process is finished, add $10 \mu \mathrm{L}$ hydrogen peroxide to substrate solution and pipette $200 \mu \mathrm{L}$ to each well of a Matrix 96-well polystyrene microtiter plates (see. Sect. 18.5, Note 15) and place plate in Kingfisher 96

9. Once beads are incubated in the substrate and color developed for $20 \mathrm{~min}$, beads are removed from the substrate by transferring them back to wash plate 4

10. Take out Substrate plate from the Kingfisher 96 instrument and measure substrate specific extinction at $405 \mathrm{~nm}$ in an ELISA reader (see Sect. 18.5, Note 16)

11. For each individual selection target, evaluate enrichment by plotting the obtained values for antigen-loaded and control beads of each phage selection rounds next to each other as depicted in Fig. 18.2

\subsubsection{Production of Soluble Monoclonal Antibody Fragments in Microtiter Plates}

Prior to the production of soluble monoclonal antibody fragments, individual clones are picked and the E. coli host strain is switched (see Sect. 18.5, Note 17). 
1. Inoculate $5 \mathrm{~mL}$ of $2 \mathrm{YT}$ in a $15 \mathrm{~mL} \mathrm{PP}$ tube with a single clone of $\mathrm{HB} 2151$ from an agar plate and grow shaking overnight at $37^{\circ} \mathrm{C}$ and $250 \mathrm{rpm}$. (see Sect. 18.5, Note 4)

2. Inoculate $50 \mathrm{~mL} 2 \mathrm{YT}$ in a $250 \mathrm{~mL}$ Erlenmeyer flask with $0.5 \mathrm{~mL}$ of overnight $\mathrm{HB} 2151$ culture and incubate shaking at $37^{\circ} \mathrm{C}$ and $250 \mathrm{rpm}$ until $\mathrm{OD}_{600}=$ 0.4-0.5. (see Sect. 18.5, Note 5)

3. Meanwhile, prepare a 1:10 dilution series of the desired panning round from the corresponding phage stock plate (see Sect. 18.3.3) by adding $10 \mu \mathrm{L}$ phage to $90 \mu \mathrm{L}$ PBST (see Sect. 18.5, Note 12)

4. Add $100 \mu \mathrm{L}$ of $E$. coli $\mathrm{HB} 2151\left(\mathrm{OD}_{600}=0.4-0.5\right)$ to phage dilutions $10^{-5}$ $10^{-8}$ and incubate for $30 \mathrm{~min}$ at $37^{\circ} \mathrm{C}$

5. Mix infected $E$. coli cultures and plate $100 \mu \mathrm{L}$ of each dilution series on a 2YT-AG agar plate. Once dried, incubate plates top-down overnight at $37^{\circ} \mathrm{C}$

6. Pick 92 clones into 96-well U-bottom PP microtiter plate filled with $200 \mu \mathrm{L}$ 2YT-AG-2. Leave positions H3, H6, H9, and H12 empty for controls. Seal mother plate with breathable sealing film and incubate in a microplate shaker overnight at $37^{\circ} \mathrm{C}$ and $1,400 \mathrm{rpm}$ (see Sect. 18.5 , Note 10)

7. Next day, inoculate fresh 96-well U-bottom PP microtiter plate containing $180 \mu \mathrm{L} 2$ YT-AG- 0.1 with $20 \mu \mathrm{L}$ of the overnight culture and incubate daughter plate for $2 \mathrm{~h}$ at $37^{\circ} \mathrm{C}$ and $1,400 \mathrm{rpm}$

8. Add $150 \mu \mathrm{L}$ glycerol solution to each well of the mother plate and store as glycerol stock at $-80^{\circ} \mathrm{C}$

9. Induce soluble antibody fragment production in daughter plate by adding $11 \mu \mathrm{L} 20 \mathrm{mM}$ IPTG (final conc. $1 \mathrm{mM}$ ) to each well and continue incubating overnight at $30^{\circ} \mathrm{C}$ and $1,400 \mathrm{rpm}$

10. Pellet bacteria by centrifugation of microtiter plates for $10 \mathrm{~min}$ at 3,000 rpm (see Sect. 18.5, Note 13)

11. Transfer soluble monoclonal antibody fragment containing culture supernatant into fresh 96-well U-bottom PP microtiter plate and store until further use at $4^{\circ} \mathrm{C}$. Discard pellet-containing plate

\subsubsection{ELISA of Soluble Monoclonal Antibody Fragments in Microtiter Plates}

For each microtiter plate of soluble monoclonal antibody fragments (92 clones), two ELISA plates must be prepared. 46 individual clones (culture plate positions A1-H6 and A6-H12, respectively) will be evaluated per ELISA plate to allow for monitoring unspecific binding on a respective negative control antigen. Proposed plate layout and an example for a monoclonal ELISA result are shown in Fig. 18.3.

1. Coat half of a Matrix 96-well microtiter plate (positions A1-H6) by transferring (a) 1-2 $\mu$ g protein antigen in $100 \mu \mathrm{L}$ PBS or (b) 10-20 ng peptide antigen 
in $100 \mu \mathrm{L}$ PBS to each well. At the same time, coat the other half of the plate (positions A7-H12) with $100 \mu \mathrm{L} /$ well of an appropriate negative control, such as Bovine Serum Albumin $(10 \mu \mathrm{g} / \mathrm{mL}$ in PBS $)$ or PTM and incubate microtiter plate overnight at $4^{\circ} \mathrm{C}$

2. Discard coating solution and wash wells $2 \times 5 \mathrm{~min}$ by completely filling them with PBST (see Sect. 18.5, Note 18)

3. Block wells by completely filling them with PTM and incubate for $1 \mathrm{~h}$ at RT

4. Discard blocking solution and wash wells $3 \times 5$ min by completely filling them with PBST

5. Fill each well with $50 \mu \mathrm{L}$ PTM and add $50 \mu \mathrm{L}$ soluble antibody fragment solution of the respective 46 clones to each half of the plate (containing target antigen and a negative control, respectively) and incubate for $1 \mathrm{~h}$ at RT. For ease of use and to avoid pipetting errors, use an eight-channel micropipette

6. Discard soluble antibody fragment solution and wash wells $3 \times 5$ min by completely filling them with PBST

7. Add $100 \mu \mathrm{L}$ of recombinant Protein L-HRP (1:5,000 in PTM) to each well and incubate for $1 \mathrm{~h}$ at RT (see Sect. 18.5, Note 19)

8. Discard recombinant Protein L-HRP solution and wash wells $3 \times 5$ min with PBST and $2 \times 5$ min with PBS by completely filling them

9. Meanwhile, prepare substrate by dissolving one ABTS tablet $(10 \mathrm{mg})$ in $20 \mathrm{~mL}$ substrate buffer. Immediately prior use, add $10 \mu \mathrm{L}$ hydrogen peroxide to the substrate solution

10. Finally, add $100 \mu \mathrm{L}$ of substrate to each well and leave to develop (change to dark green color) for 5-30 min at RT in the dark

11. Measure substrate-specific extinction at $405 \mathrm{~nm}$ in an ELISA reader (see Sect. 18.5, Note 16)

12. Plot the obtained values for antigen and negative control protein for each soluble monoclonal antibody fragment next to each other and identify positive candidates with an acceptable (usually >tenfold) signal to background ratio (Fig. 18.3)

\subsection{Results and Conclusion}

This semi-automated magnetic bead-based selection protocol allows the isolation of recombinant antibodies from phage display libraries against multiple targets simultaneously. The throughput is dependent on which magnetic particle processor is available in the laboratory. Currently, the highest number of parallel selections can be performed on Thermo Scientific's Kingfisher 96 and derivatives (Kingfisher Flex or Qiagen Biosprint 96). Essentially, any of these processors can be used to perform phage display selections. The selection protocol can be amended to any of the available systems since the key parameters, such as incubation time, speed of motion, and number and volume of washing steps, can be programmed accordingly. 
Next to the automated panning protocol, a number of key methods are designed to accommodate the throughput of multiple simultaneous selections. Phage infection, propagation, isolation, and titration protocols are simplified and adapted for use on microtiter plate format. An additional benefit is the reduction of time required per selection round with streamlined processes. A single selection round can be performed within a day, thus allowing the entire panning process to be completed in a week. For the evaluation steps consisting of polyclonal antibody phage ELISA and soluble monoclonal antibody fragment ELISA, standard operating procedures have been set up. Use of standardized plate layouts and Microsoft Excel Worksheet templates allows fast and easy data handling of a multitude of assay results. Figure 18.2 shows a typical ELISA result highlighting the enrichment patterns of antibody phage selection over four rounds. Enrichment is frequently observed starting in round 3 and/or round 4 . A typical result for soluble monoclonal antibody fragment ELISA is shown in Fig. 18.3. Signal intensities as well as signal-tobackground ratios can vary because of the amount and quality of the selection target.

As an alternative to performing selections against up to 96 target proteins in parallel, the number of selection targets can be reduced and the complexity of selection parameters increased. For instance, biological parameters can be changed, i.e., different antibody libraries can be applied, or different helper phage systems can be used for initial packaging of the same library (e.g., Hyperphage versus M13K07; see Soltes et al. 2007), or even different E. coli strains can be used for phage propagation. Furthermore, different buffer conditions or counter selection strategies can be introduced. This could be of great value, for example, when antibodies against certain splice variants or post translational modifications of a protein need to be selected. In such a case, increased amounts of a nonbiotinylated unwanted protein variant can be added at various steps for counter selection, such as washing steps or even the selection step of rounds $2-4$ itself.

In summary, the semi-automated selection protocol allows performing up to 96 phage display selections in parallel. While its strength is the use of standard operating procedures in respect to technical parameters of magnetic bead handling, the system allows a high degree of flexibility in selection design. Until now, we have successfully applied the protocols described here to select antibody fragments against many different types of targets, such as peptides, recombinant or homologous proteins, or chemical compounds.

\subsection{Notes and Troubleshooting}

1. The human single-fold scFv libraries I and $\mathrm{J}$ (Tomlinson I and $\mathrm{J}$ ) were created in Greg Winter's lab at the MRC Laboratory of Molecular Biology and the MRC Center for Protein Engineering (Cambridge, UK). Further information on the libraries can be found at the distributor's website: http://www.geneservice. co.uk/products/proteomic/scFv_tomlinsonIJ.jsp (Cited 7 May 2009). Using 
other than these combinatorial antibody phage display libraries might need some library-specific adaptation to the individual protocols.

2. The beads are retained in the cups while exchanging solutions by placing cups in a magnetic stand, such as a DynaMag ${ }^{\mathrm{TM}}-2$ magnet (Invitrogen Dynal AS). Incubations are carried out using a rotator, such as Rotators SB2 or SB3 (Carl Roth, Karlsruhe, Germany).

3. In case the target antigen is not already biotinylated, it can be in vitro biotinylated with commercially available biotinylation reagent kits, such as the NHSSS-Biotin (sulfosuccinimidyl-2-(biotinamido)ethly-1,3-dithiopropionate) from Pierce.

4. Maintenance of F' episome in TG1 and HB2151 cells requires regular passaging on Minimal (M9) agar plates. For details see Sambrook et al. 1989.

5. For infection, filamentous bateriophages require the $E$. coli cells to possess pili. $E$. coli cells carrying the F' episome form pili mainly during the logarithmic growth phase. If cells reach $\mathrm{OD}_{600}=0.4-0.5$ before they are needed, cells can be arrested with formed pili for $\sim 30 \mathrm{~min}$ by placing on ice.

6. The wash volume can be increased up to $1 \mathrm{~mL}$ when using Deep Well 96 Plates (Thermo Scientific). Further, the number of wash plates per selection cycle can be freely changed or washing solutions can be varied (see Sect. 18.4).

7. Incubation times, speed of up-and-down movement, and incubation temperature can be varied. If incubation times exceed $30 \mathrm{~min}$, some types of beads can settle at the bottom of the plate. To circumvent this, recollect beads every 20-30 min, during the incubation, with magnet.

8. If titration of bound phages during the panning protocol is desired, take $10 \mu \mathrm{L}$ of magnetic bead suspension from release plate and titer according to Sect. 18.3.4.

9. Once the E. coli culture plate is infected with phage particles (on magnetic beads), we refer to it as selection stock plate.

10. Dedicated microplate incubator shakers, such as iEMS (Thermo Scientific) or PST-60HL-4, Lab4You, Berlin, Germany) are able to shake $>1,200 \mathrm{rpm}$, ensuring best possible aeration of the cultures in combination with breathable sealing tapes. This is of highest importance during phage particle production but also beneficial during soluble antibody fragment production.

11. Prepare a fresh overnight culture from selection stock plate glycerol stock (see Sects. 18.3.2 and 18.3.3) by inoculating fresh 96-well U-bottom PP microtiter plate containing $180 \mu \mathrm{L} 2$ YT-AG-2 with $20 \mu \mathrm{L}$ of glycerol stock and incubate overnight at $37^{\circ} \mathrm{C}$ and $1,400 \mathrm{rpm}$. Next day, inoculate fresh 96-well U-bottom PP microtiter plate containing $200 \mu \mathrm{L} 2$ YT-AG-0.1 with $20 \mu \mathrm{L}$ of the overnight culture and incubate plate for $2 \mathrm{~h}$ at $37^{\circ} \mathrm{C}$ and 1,400 rpm. Transfer culture into 96 -well filtration plate and continue with step 2 of Sect. 18.3.3.

12. Filter tips should be used throughout all experimental steps involving phage particles.

13. Microtiter plates can be centrifuged in Eppendorf $5810 \mathrm{R}$ with swing out rotor A-4-62 and microplate holders. As an alternative to centrifugation, a 


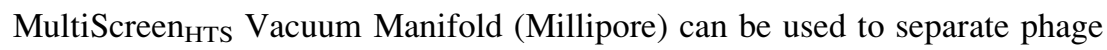
particle containing media from bacterial cell mass.

14. In addition to the phage dilutions, all used solutions should be assayed for phage contamination (mock-infections) and should be plated out together with the noninfected $E$. coli on selective agar plates.

15. To avoid magnetic beads sticking to polystyrene surface of Matrix 96-well plate, block wells by completely filling them with PTM and incubate for $1 \mathrm{~h}$ at RT prior use.

16. If function is available, set reader to shake/mix plate before reading. This will ensure proper dispersion of the developed color due to enzymatic breakdown of the substrate.

17. Host strain switching is advantageous for high level expression of antibody fragments from the Tomlinson libraries I and $\mathrm{J}$, since an amber stop codon is inserted between the antibody fragment and the gIII. In the E. coli strain HB2151, this amber stop is not suppressed, and therefore, only antibody fragments without pIII fusion are produced. Furthermore, expression of the phage coat protein pIII can be toxic for the host at higher concentrations.

18. If available, microtiter plates can be washed using an ELISA washer (e.g., TECAN Columbus Plus, Crailsheim, Germany). Otherwise, microtiter plates can be washed manually by either filling the plates with a multichannel pipette or by submerging plates in wash solution filled plastic tanks (2-5 L volume). Plates are emptied by simply shaking out the plates after each washing step into a waste tank and tapped dry on a clean linen-free towel.

19. Recombinant Protein L binds only to human V-Kappa light chains. In cases other than where the Tomlinson I and $\mathbf{J}$ antibody phage display libraries are used, the recombinant Protein L-HRP needs to be substituted with an appropriate, tag-dependent detection antibody, e.g. a mouse anti-myc-tag monoclonal antibody (9E10, SIGMA-ALDIRCH).

Acknowledgments This work was supported by the German Federal Ministry for Education and Research (BMBF) through the National Genome Research Network (NGFN-II) project "Antibody Factory" (Grant No. 01GR0427) and the Max Planck Society. ZK acknowledges additional support from EU-FP6 CA "Proteome Binders" (RICA. 026008). TSL gratefully acknowledges financial support from the Ministry of Higher Education Malaysia and Institute for Research in Molecular Medicine, University Science Malaysia.

\section{References}

Barbas CF III, Kang AS, Lerner RA, Benkovic SJ (1991) Assembly of combinatorial antibody libraries on phage surfaces: the gene III site. Proc Natl Acad Sci USA 88:7987-7992

Boder ET, Wittrup KD (1997) Yeast surface display for screening combinatorial polypeptide libraries. Nat Biotechnol 15:533-557

Breitling F, Dübel S, Seehaus T, Klewinghaus I, Little M (1991) A surface expression vector for antibody screening. Gene 104:147-153 
Buckler DR, Park A, Viswanathan M, Hoet RM, Ladner RC (2008) Screening isplates from antibody phage display libraries. Drug Discov Today 13:318-324

Cohen S, Trinka RF (2002) Fully automated screening systems. Methods Mol Biol 190:213-228

de Wildt RM, Mundy CR, Gorick BD, Tomlinson IM (2000) Antibody arrays for high-throughput screening of antibody-antigen interactions. Nat Biotechnol 18:989-994

Dübel S (2007) Handbook of therapeutic antibodies. Wiley-VCH, Weinheim

Fukuda I, Kojoh K, Tabata N, Doi N, Takashima H, Miyamoto-Sato E, Yanagawa H (2006) In vitro evolution of single-chain antibodies using mRNA display. Nucleic Acids Res 34:e127

Hallborn J, Carlsson R (2002) Automated screening procedure for high-throughput generation of antibody fragments. Biotechniques Suppl: $30-37$

Hamilton S (2002) Introduction to screening automation. Methods Mol Biol 190:169-193

Hanes J, Plückthun A (1997) In vitro selection and evolution of functional proteins by using ribosome display. Proc Natl Acad Sci USA 94:4937-4942

Hawlisch H, Müller M, Frank R, Bautsch W, Klos A, Köhl J (2001) Site-specific anti-C3a receptor single-chain antibodies selected by differential panning on cellulose sheets. Anal Biochem 293:142-145

Hust M, Maiss E, Jacobsen HJ, Reinard T (2002) The production of a genus specific recombinant antibody (scFv) using a recombinant potyvirus protease. J Virol Methods 106:225-233

Kala M, Bajaj K, Sinha S (1997) Magnetic bead enzyme-linked immunosorbent assay (ELISA) detects antigen-specific binding by phage-displayed scFv antibodies that are not detected with conventional ELISA. Anal Biochem 254:263-266

Konthur Z (2007) Automation of Selection and Engineering. In: Dübel S (ed) Handbook of therapeutic antibodies. Wiley-VCH, Weinheim, pp 413-431

Konthur Z, Crameri R (2003) High-throughput application of phage display in proteomic analyses. Targets 2:261-270

Konthur Z, Walter G (2002) Automation of phage display for high-throughput antibody development. Targets 1:30-36

Konthur Z, Hust M, Dübel S (2005) Perspectives for systematic in vitro antibody generation. Gene 364:19-29

Krebs B, Rauchenberger R, Reiffert S, Rothe C, Tesar M, Thomassen E, Cao M, Dreier T, Fischer D, Höss A, Inge L, Knappik A, Marget M, Pack P, Meng XQ, Schier R, Söhlemann P, Winter J, Wölle J, Kretzschmar T (2001) High-throughput generation and engineering of recombinant human antibodies. J Immunol Methods 254:67-84

Li M (2000) Applications of display technology in protein analysis. Nat Biotechnol 18:1251-1256

McCafferty J, Griffiths AD, Winter G, Chiswell DJ (1990) Phage antibodies: filamentous phage displaying antibody variable domains. Nature 348:552-554

McConnell SJ, Dinh T, Le MH, Spinella DG (1999) Biopanning phage display libraries using magnetic beads vs. polystyrene plates. Biotechniques 26(208-10):214

Menke KC (2002) Unit automation in high throughput screening. Methods Mol Biol 190: $195-212$

Mondon P, Dubreuil O, Bouayadi K, Kharrat H (2008) Human antibody libraries: a race to engineer and explore a larger diversity. Front Biosci 13:1117-1129

Noppe W, Plieva F, Galaev IY, Pottel H, Deckmyn H, Mattiasson B (2009) Chromato-panning: an efficient new mode of identifying suitable ligands from phage display libraries. BMC Biotechnol 9:21

Parmley SF, Smith GP (1988) Antibody selectable filamentous fd phage vectors: affinity purification of target genes. Gene 73:305-318

Rhyner C, Konthur Z, Blaser K, Crameri R (2003) High-throughput isolation of recombinant antibodies against recombinant allergens. Biotechniques 35:672-674

Sambrook T, Fritsch FF, Maniatis T (1989) Molecular cloning - A laboratory manual, 2nd edn. Cold Spring Harbor Laboratory Press, Cold Spring Harbor

Soltes G, Hust M, Ng KK, Bansal A, Field J, Stewart DI, Dübel S, Cha S, Wiersma EJ (2007) On the influence of vector design on antibody phage display. J Biotechnol 127:626-637 
Taussig MJ, Stoevesandt O, Borrebaeck CA, Bradbury AR, Cahill D, Cambillau C, de Daruvar A, Dübel S, Eichler J, Frank R, Gibson TJ, Gloriam D, Gold L, Herberg FW, Hermjakob H, Hoheisel JD, Joos TO, Kallioniemi O, Koegl M, Konthur Z, Korn B, Kremmer E, Krobitsch S, Landegren U, van der Maarel S, McCafferty J, Muyldermans S, Nygren PA, Palcy S, Plückthun A, Polic B, Przybylski M, Saviranta P, Sawyer A, Sherman DJ, Skerra A, Templin M, Ueffing M, Uhlen M (2007) ProteomeBinders: planning a European resource of affinity reagents for analysis of the human proteome. Nat Methods 4:13-17

Thie H, Meyer T, Schirrmann T, Hust M, Dübel S (2008) Phage display derived therapeutic antibodies. Curr Pharm Biotechnol 9:439-445

Turunen L, Takkinen K, Söderlund H, Pulli T (2009) Automated panning and screening procedure on micorplates for antibody generation from phage display libraries. J Biomol Screen 14: 282-293

Walter G, Konthur Z, Lehrach H (2001) High-throughput screening of surface displayed gene products. Comb Chem High Throughput Screen 4:193-205 